\title{
A EXTENSÃO UNIVERSITÁRIA EM UM POLO DE EDUCAÇÃO A DISTÂNCIA: O CASO DE NOVA FRIBURGO/RJ
}

Sergio Roberto Pinho Júnior | sergiopinhobiologia@gmail.com

Estudante do curso de Licenciatura em Ciências Biológicas da UERJ no Polo EaD de Nova Friburgo. Bolsista do DEPEXT/UERJ em pesquisas sobre as relações da Internet e de suas ferramentas com a Educação, o Ensino e a Extensão Universitária.

Fátima Kzam Damaceno de Lacerda | fatima_kzam@yahoo.com.br

Doutorado em Meio Ambiente pela Universidade do Estado do Rio de Janeiro (PPGMA/ UERJ).

Professora Adjunta do Instituto de Química da UERJ, Coordenadora Adjunta da UAB/UERJ.

Patricia Seefelder Assis | patricia@iprj.uerj.br

Doutorado em Informática pela Pontifícia Universidade Católica do Rio de Janeiro. Responsável pela área de Educação a Distância da Universidade Estadual do Rio de Janeiro, Campus Regional de Nova Friburgo/ Instituto Politécnico (IPRJ).

Antonio Nunes Oliveira | antonionunesdeoliveira@yahoo.com.br

Graduação em Informática e Especialização em Planejamento, Implementação e Gestão da Educação a Distância pela Universidade Federal Fluminense (UFF). Apoio técnico de informática e tutor do CEDERJ.

\section{Resumo}

Este artigo tem como objetivo discutir a importância da relação entre uma instituição promotora de cursos EaD em nível superior, seus estudantes e a comunidade. Para isso, é apresentado um breve histórico das atividades realizadas no Polo EaD de Nova Friburgo em seus 10 anos de existência, com foco naquelas relacionadas à extensão universitária. Destaca-se a utilização do blog do polo, criado em setembro de 2010 , com o intuito de funcionar como mais um canal de comunicação entre instituição, estudantes e comunidade. Vale observar que as relações instituição-estudante e instituição-comunidade podem ser tão importantes para a formação dos estudantes quanto a relação estudante-professor, geralmente a mais abordada em estudos sobre EaD. A valorização de tais relações contribui para uma $\mathrm{EaD}$ com mais qualidade para seus estudantes e maior interação com a sociedade.

\section{Palavras-chave}

Educação a Distância. Extensão Universitária. Blog 


\section{The university extension in a pole of Distance Education: the case of Nova Friburgo/RJ}

\section{Abstract}

The aim of this article is to discuss the importance of the relationship between an institution that promotes e-learning undergraduate courses, its students and the community. To that end, we present a brief history of the activities developed at the e-learning pole of Nova Friburgo in its 10 years of existence, focused on those related to the University outreach. We emphasize the use of a blog, created on September 2010, in order to serve as another channel of communication between the institution, the students and the community. It is important to note that the institution-student and institution-community relations can be as important to the student under graduation as the student-lecturer relation, generally more studied in the e-learning context. Furthermore, we intent to contribute to a more quality e-learning experience for its students and a greater interaction with the society as well.

\section{Keywords}

Distance Education. University Extension. Blog.

\section{Introdução}

Como apontam diversos autores, a Educação a Distância $(\mathrm{EaD})$ é uma modalidade muito democrática de Educação, pois universaliza as oportunidades de acesso ao conhecimento (ALVES, 2011; LOPES et al, 2007), permitindo que pessoas impossibilitadas de frequentar a universidade nos locais e horários convencionais tenham acesso ao ensino superior (GRANATO et al, 2010).

Porém, o que se nota nos estudos sobre $\mathrm{EaD}$ é que há grande enfoque na relação aluno-professor (MACHADO et al, 2013) - que nessa modalidade é diferenciada, geralmente por intermédio das novas Tecnologias de Informação e Comunicação (NTIC), podendo ocorrer encontros presenciais em menor quantidade -, mas pouco se discute sobre as relações instituição-aluno $e$ instituição-comunidade, também muito importantes.

A Constituição Federal de 1988 estabelece a obrigatoriedade da integração entre ensino, pesquisa e extensão nas universidades brasileiras (BRASIL, 1988). Com base na Política Nacional de Extensão Universitária elaborada no Fórum de Pró-Reitores de Extensão das Universidades Públicas Brasileiras (FORPROEX, 2012), é possível afirmar que a extensão universitária

\begin{abstract}
é um processo educativo, cultural e científico que articula o Ensino e a Pesquisa de forma indissociável e viabiliza a relação transformadora entre a universidade e a sociedade, com base na interlocução entre saberes, que tem como consequências a produção do conhecimento resultante do confronto com a realidade, a democratização do conhecimento acadêmico e a participação efetiva da comunidade na atuação da universidade. Além de instrumentalizadora desse processo dialético de teoria/prática/reflexão/prática, a Extensão Universitária é interdisciplinar, favorecendo a visão integrada de todas as dimensões da realidade social. A extensão promove uma relação entre a universidade e outros setores da sociedade e está voltada para os interesses e necessidades da maioria da população, atuando como implementadora de desenvolvimento regional e de políticas públicas. Esta relação dialógica é marcada pela ação de mão dupla, de troca de saberes, e de superação do discurso de hegemonia acadêmica, cujas ações são caracterizadas pelo seu caráter interdisciplinar, buscando a indissociabilidade ensino-pesquisa-extensão, fundamental na formação de um profissional cidadão (http://proex.ufpa. br/PRINCIPAL/index.php/politica-de-extensao).
\end{abstract}

Por este artigo, objetiva-se defender a ideia de que os polos de Educação a Distância podem (e devem) interagir com seus alunos e com a comunidade, mediante práticas de extensão que aumentem a visibilidade da universidade, assim como sua relevância social e acadêmica, contribuindo para o estabelecimento de uma EaD mais pessoal e significativa para os estudantes e cuja imagem não seja de uma educação emergencial, de baixa qualidade e ineficiente na formação do cidadão. 
Para tal, é apresentada a experiência desenvolvida no Polo de Nova Friburgo/RJ, com destaque para a criação e manutenção de um blog por uma equipe que envolve a participação de estudantes de cursos semipresenciais de graduação.

\section{O polo de Educação a Distância de Nova Friburgo}

O Polo de Nova Friburgo é uma referência na área de formação docente, graduando e capacitando professores no Estado do Rio de Janeiro (LACERDA, 2010). Além de Nova Friburgo, sua atuação se estende aos municípios vizinhos: Bom Jardim, Cachoeiras de Macacu, Cantagalo, Carmo, Duas Barras, Itaboraí, Macuco, São Gonçalo, Sumidouro, Teresópolis e Trajano de Moraes.

Além de cursos de graduação semipresenciais, o polo oferece também cursos de extensão online em várias áreas do conhecimento para professores das redes pública e particular de ensino; um curso (presencial) preparatório para o vestibular, destinado a estudantes de baixa renda - o chamado Pré-Vestibular Social (PVS) - e o curso de pós-graduação lato sensu a distância em Educação Tecnológica, oferecido pelo Centro Federal de Educação Celso Suckow da Fonseca (CEFET-RJ), pelo Sistema Universidade Aberta do Brasil (UAB).

Gradativamente, as atividades extensionistas foram se somando às atividades de ensino e passaram a fazer parte do cotidiano do polo.

\subsection{Um breve histórico do polo e suas atividades de extensão}

Instaurado em agosto de 2003, no Campus Regional Instituto Politécnico do Rio de Janeiro (IPRJ), unidade acadêmica da Universidade do Estado do Rio de Janeiro (UERJ), o Polo de Nova Friburgo oferecia apenas o curso de Licenciatura em Pedagogia para as Séries Iniciais, diplomado pela UERJ, por meio do
Centro de Educação a Distância do Estado do Rio de Janeiro (Consórcio CEDERJ).

Já em seus primeiros meses de funcionamento, o polo investiu em extensão, tendo participado de atividades como a $1^{\text {a }}$ Feira de Informação Profissional do Colégio Nossa Senhora das Dores (CNSD/NF) e de uma oficina de contação de histórias, além de ter realizado uma atividade de "portas abertas" simultaneamente com o evento UERJ Sem Muros e de ter levado seus estudantes para visitar o Campus Maracanã, o que acabou por se tornar uma tradição.

No ano de 2004, diversas oficinas foram oferecidas, como as de produção de texto científico e Alfabetização. Em 2005, além do UERJ Sem Muros, o polo participou da Semana Nacional de Ciência e Tecnologia (SNCT) e realizou a $1^{\text {a }}$ Semana de Pedagogia do Polo de Nova Friburgo, cujas atividades visavam estimular os estudantes do polo a envolverem-se no meio acadêmico.

A partir de fevereiro de 2006, o polo passou a oferecer o curso de Licenciatura em Ciências Biológicas, também diplomado pela UERJ, e a organizar anualmente o Encontro de Graduação do Polo de Nova Friburgo, cujas atividades envolvem palestras, minicursos e apresentações musicais.

Em janeiro de 2007, fortes chuvas causaram a interdição do acesso ao IPRJ, e o polo funcionou de forma provisória no Colégio Estadual Professor Jamil El Jaick (CEJE). Mesmo em instalações improvisadas, os alunos organizaram o $1^{\circ}$ Encontro dos Estudantes de Biologia ( $1^{\circ}$ ENBIO), o $2^{\circ}$ Encontro de Graduação do Polo de Nova Friburgo e a SNCT, com atividades abertas também à comunidade.

De volta ao IPRJ, em 2008, o curso de Pedagogia para as Séries Iniciais foi substituído pelo curso de Licenciatura em Pedagogia (UERJ), e o polo foi inserido também no sistema UAB. Foram realizados o $2^{\circ}$ ENBIO, o $3^{\circ}$ Encontro de Graduação e a SNCT.

Em 2009, além dos eventos já consagrados (oficinas, feiras de orientação profissional, encontros acadêmicos), o polo organizou, em parceria com a Secretaria de Educação de Nova Friburgo, a 
Caravana da Ciência/UERJ Ciência na Praça Getúlio Vargas, no centro da cidade, com a participação de seus estudantes como monitores. Organizou ainda, em conjunto com o IPRJ, o evento Quartas Científicas, com palestras sobre temas diversos, abertas à sociedade, e levou a Oficina de Artes do Departamento de Extensão da UERJ (DEPEXT) para o IPRJ.

Em setembro de 2010, teve início o Projeto de Inovação em Educação a Distância, originalmente dentro do Programa Inovação Tecnológica do Conselho Nacional de Desenvolvimento Científico e Tecnológico (PIBIT/CNPq), que possibilitou a criação do blog do Polo de Nova Friburgo, conforme será discutido.

Devido à tragédia climática ocorrida na região serrana do Estado do Rio de Janeiro, em 2011 o acesso ao IPRJ foi novamente interditado e o polo precisou funcionar em duas diferentes instituições: na Escola Municipal Dante Magliano e no Colégio Estadual Doutor João Bazet, realizando suas atividades de forma simultânea em ambos os espaços. Porém, mesmo com as adversidades, esse foi um ano academicamente rico para o polo. Em março desse ano foi criado o projeto Ciência e Cultura, em que as atividades também são feitas a distância, com o intuito de oficializar as ações extensionistas do polo, envolvendo alunos e instituições parceiras na criação de uma cultura acadêmica de integração entre as diversas áreas do conhecimento (ARAÚJO et al, 2011). Assim, atividades das mais diferentes características foram realizadas nos espaços cedidos: oficinas e palestras; mostras culturais e artísticas; exibições de filmes; debates com políticos sobre a situação da cidade, da região e do polo por causa da tragédia; visitas docentes; encontros acadêmicos; apresentações artísticas e comemorações, como a do aniversário de oito anos do polo.

Além disso, também foi estimulada a participação de alunos em eventos realizados em outros espaços. Estudantes do polo participaram como ouvintes ou apresentaram trabalhos em diversos eventos, como a $22^{\mathrm{a}}$ UERJ Sem Muros (Rio de Janeiro/RJ), IV Con- gresso de Biólogos dos Estados do Rio de Janeiro e Espírito Santo (IV CBIO, Rio de Janeiro/RJ); VIII Congresso Brasileiro de Ensino Superior a Distância (VIII ESUD, Ouro Preto/MG) e V Congresso Brasileiro de Extensão Universitária (V CBEU, Porto Alegre/RS), entre outros.

Em 2012, ocorreu a mudança definitiva do polo para o CIEP 124 Licínio Teixeira, no bairro de Olaria. Aos cursos de Licenciaturas em Pedagogia e Ciências Biológicas, somou-se o curso de Licenciatura em Letras, diplomado pela Universidade Federal Fluminense (UFF). A interação do polo com as escolas do município continuou, assim como a oferta de atividades acadêmicas e culturais para alunos e a comunidade. Mais uma vez, estudantes do polo promoveram a EaD apresentando seus trabalhos em eventos de diferentes instituições, como o VI Encontro Regional de Ensino de Biologia (VI EREBIO, Rio de Janeiro/RJ) e a $23^{\mathrm{a}}$ UERJ Sem Muros (Rio de Janeiro/RJ).

Em 2013, o polo passou a oferecer também o curso de Licenciatura em Geografia, diplomado pela UERJ. Alguns eventos que aconteceram com grande contribuição dos estudantes foram: aulas inaugurais e recepção aos calouros; comemoração do Dia do Pedagogo (evento com palestras, apresentações musicais e circenses); feiras de orientação profissional em escolas da cidade; visitas a um abrigo de idosos (com entrega de doações) e comemoração do aniversário de 10 anos do polo. Além disso, o número de estudantes do polo participando de eventos promovidos por outras instituições, como autores e/ou apresentadores de trabalhos, aumentou consideravelmente. No I Seminário das Disciplinas Pedagógicas das Licenciaturas EaD, realizado pela UERJ (Campus Maracanã), por exemplo, o Polo de Nova Friburgo foi o que mais contribuiu com autores de trabalho: 15 , somando-se alunos e tutores.

Outros eventos em que estudantes do polo participaram apresentando trabalhos foram: $\mathrm{X}$ ESUD (Belém/PA); seminário Questões para a Agenda da Escola Contemporânea (CNSD/NF); $24^{\mathrm{a}}$ UERJ Sem Muros (Rio de Janeiro/RJ); XI Con- 
gresso de Ecologia do Brasil (XI CEB, Porto Seguro/BA); V Simpósio Brasileiro de Agropecuária Sustentável (V SIMBRAS, Viçosa/MG); e I Exposição de Trabalhos Acadêmicos da Região Serrana (I ETARSERRA, Nova Friburgo/RJ). Neste último, recebeu menção honrosa por sua relevância o trabalho A EaD expandindo as Fronteiras da universidade: o blog em questão (PINHO JÚNIOR et al, 2013), que relata a extensão universitária no Polo de Nova Friburgo em seus 10 anos de atuação e o papel do blog do polo nessa área.

\section{O blog do Polo de Nova Friburgo}

Um blog é um espaço/ferramenta da internet que permite a um autor abordar qualquer tema de seu interesse de forma multimidiática, hipertextual $e$ interativa, por meio de mensagens denominadas postagens (também chamadas posts) que geralmente são apresentadas em ordem cronológica inversa (as mais recentes primeiro) (GOMES, 2005). Outra característica a ser enfatizada é a facilidade de criação e manutenção dos blogs, possibilitada pela existência de servidores na internet que fornecem todas as ferramentas necessárias, inclusive de forma gratuita (PINHO JÚNIOR et al, 2011).

Devido às suas características, o blog constitui-se num espaço de fácil acesso e que possibilita a exploração de uma maior gama de percepções sensoriais no receptor, estabelecendo-se assim, de acordo com Silva (2010), como um dos melhores recursos de transmissão de informação. Essas propriedades, se bem exploradas, podem contribuir em diferentes áreas da Educação, não só no ensino formal como também na extensão universitária, como exposto neste trabalho.

Iniciado em setembro de 2010, com o Projeto de Inovação em Educação a Distância, o blog do Polo de Nova Friburgo apresenta os seguintes objetivos (PINHO JÚNIOR et al, 2011):

- Criar mais um meio de contato com estudantes e comunidade externa;
- Aumentar a visibilidade do polo e de suas ações;

- Aumentar o sentimento de pertencimento dos estudantes da $\mathrm{EaD}$ à universidade;

- Diminuir os índices de evasão;

- Minimizar os preconceitos que ainda existem em relação à EaD (LÜCK, 2008).

\subsection{Metodologia}

O blog do Polo de Nova Friburgo caracterizase por ser um trabalho colaborativo. Em seu formato atual, um estudante bolsista, responsável pela criação e edição dos conteúdos postados, elabora o material que é revisado - tanto no que diz respeito à forma como ao conteúdo - pelos demais componentes da equipe (PINHO JÚNIOR et al, 2011). Além do bolsista, fazem parte da equipe: a professora orientadora do projeto; a diretora do polo; o tutor de informática e uma funcionária do IPRJ com doutorado na área de informática. Alguns estudantes atuam como voluntários no projeto, enviando textos e ideias para serem veiculados no blog. A comunicação entre a equipe é realizada em um grupo de discussão na internet.

O WordPress foi a plataforma utilizada para gerenciar o blog, por disponibilizar ferramentas que permitem a aquisição de dados estatísticos que servem para o acompanhamento do alcance do trabalho. $\mathrm{O}$ endereço do blog é http://polofriburgo.wordpress.com/.

Os conteúdos são divididos de acordo com a sua natureza e são inseridos em páginas (divididas por menus) ou postagens (divididas em categorias) bem definidos em seus espaços, a fim de manter controle sobre o que é apresentado no blog, como pode ser visto na Figura 1. Algumas páginas possuem conteúdo meramente informativo, como as que relatam a história da instituição e da EaD. Nas postagens ou páginas sobre os eventos ocorridos no polo, a possibilidade e a presença de comentários mostram ao visitante que ele pode interagir com o meio acadêmico, inserindose nele ou simplesmente atuando como observador. 


\section{Polo EAD de Nova Friburgo}
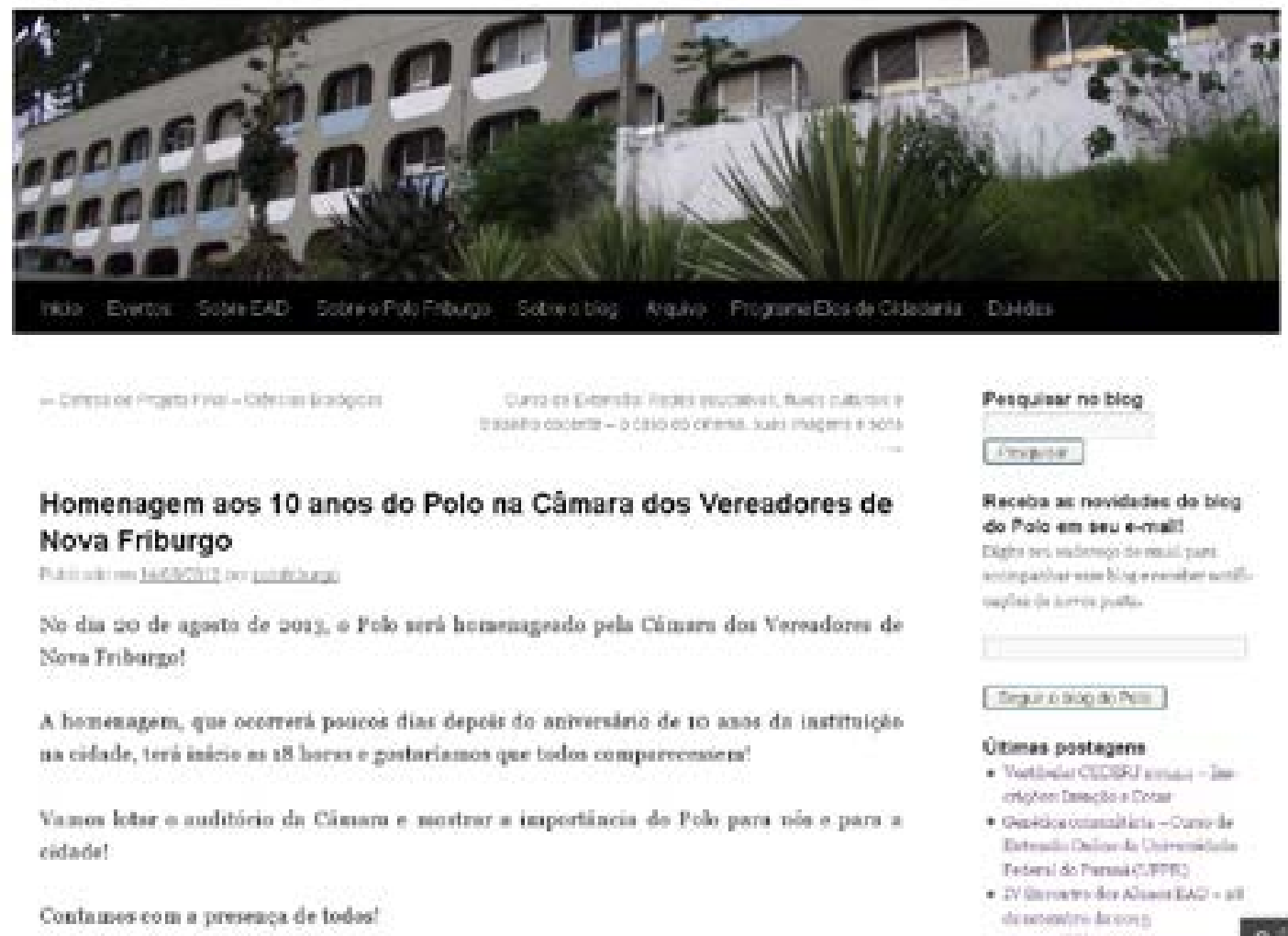

Figura 1: O blog do Polo de Nova Friburgo.

Desde sua criação, o blog vem divulgando, para os estudantes e para a comunidade em geral, as atividades acadêmicas e culturais realizadas no Polo de Nova Friburgo. A documentação de tais eventos, com textos, fotos e vídeos, fica arquivada no próprio blog, permitindo ao aluno $\mathrm{EaD}$ e à comunidade experimentar o meio acadêmico, mesmo sem estarem presentes fisicamente. Além dos assuntos do polo, o blog também serve como meio de divulgação de diversas outras informações interessantes, como inscrições para cursos (presenciais ou online); oportunidades de estágios e bolsas; vestibulares; divulgação de eventos de outras instituições; entre outras.

Além da difusão e exposição do meio acadêmico, o blog também se caracteriza como um meio de produção e difusão de conhecimento. As páginas sobre os eventos destacam não só as atividades realizadas, mas também os temas dessas atividades. As discussões dos eventos são enriquecidas, no espaço do blog, com pesquisas sobre o tema, além do uso de imagens, vídeos, textos e links, proporcionando uma abordagem mais completa dos assuntos. Assim, o blog complementa e expande as discussões realizadas em momentos presenciais no polo, trazendo para o ensino as atividades de pesquisa e extensão. Vale ressaltar que isso também pode ocorrer no ensino presencial: professores podem utilizar essa ferramenta para apresentar a seus alunos conteúdos que nem sempre têm oportunidade de transmitir no espaço das salas de aula (como vídeos, por exemplo), seja por impossibilidades materiais ou pela falta de maior tempo disponível (PINHO JÚNIOR e OLIVEIRA, 2013).

Com a finalidade de aumentar o número de visualizações do blog, a partir do final de 2012 a equipe passou a utilizar sistematicamente a rede social Facebook, compartilhando as postagens do blog nos grupos de alunos e funcionários do polo desta rede.

Outra ação importante foi a criação de um canal 
do polo no YouTube. Esse canal armazena principalmente vídeos das atividades realizadas no polo. Assim, quem não pôde comparecer a determinada palestra ou apresentação artística pode assistir a ela posteriormente. Isso representa uma expansão que, segundo Lévy (1997, apud BOHADANA; VALLE, 2009), quebra os limites espaço-temporais: eventos ocorridos no ambiente físico do polo passam a ser disponibilizados para qualquer pessoa, em qualquer local, a qualquer momento. Os materiais disponibilizados nesse canal integram as postagens no blog e são compartilhados também à parte em grupos no Facebook.

Em julho de 2013 foi realizada uma pesquisa de opinião sobre o blog (anônima e online), na qual foram coletados dados relevantes sobre os resultados do blog. Um link com um questionário foi postado diretamente no blog e foi realizada ampla divulgação no
Facebook. O questionário era composto de onze perguntas (abertas e fechadas), além de um espaço para comentários. As perguntas versavam sobre a relevância e os pontos positivos e negativos do blog do Polo de Nova Friburgo. Alguns resultados dessa pesquisa são apresentados no final da próxima seção.

\section{Resultados e discussões}

O blog já tem mais de 200 postagens e 85 páginas, nas quais textos, links, imagens, fotos e vídeos se complementam, de forma que a abordagem seja a mais completa e atraente possível. A quantidade de material postado aumenta a cada ano, como pode ser observado na Tabela 1, elaborada considerando os dados disponíveis no WordPress em novembro de 2013.

Tabela 1: Quantidade total e média de posts e páginas do blog do Polo de Nova Friburgo a cada ano

\begin{tabular}{c|c|c|c|c}
\hline Ano & Total de posts & Média de posts por mês & $\begin{array}{c}\text { Total de páginas } \\
\text { relatando eventos }\end{array}$ & $\begin{array}{c}\text { Média de páginas relatando } \\
\text { eventos por mês }\end{array}$ \\
\hline $2010^{*}$ & 13 & 3,25 & 05 & 1,25 \\
\hline 2011 & 46 & 3,83 & 30 & 2,50 \\
\hline 2012 & 61 & 5,08 & 10 & 0,83 \\
\hline 2013 & 93 & 7,75 & 20 & 1,66 \\
\hline
\end{tabular}

* Em 2010, são contabilizados apenas quatro meses, uma vez que o blog teve início em setembro.

Sobre a visível redução no relato de eventos em 2012, vale ressaltar que esse foi o ano em que o polo foi reorganizado em um novo espaço físico, processo que demandou muito tempo e esforço de toda a equipe. Em 2013, o crescimento na quantidade de páginas-relato coincide com a normalização das atividades acadêmicas e culturais realizadas no polo. No entanto, nota-se que, mesmo com a redução no número de páginas-relato, a quantidade de material online disponibilizado pelo polo só cresceu: desde o início do blog, a média de postagens em sua página inicial aumentou em mais de quatro por mês, elevando significativamente a quantidade de postagens por ano. Além disso, ao disponibilizar conteúdos também no YouTube e compartilhar informações de ambos os canais (blog e YouTube) no Facebook, o polo expandiu o seu alcance de forma relevante, conforme será discutido.

Em pouco mais de três anos de existência, o blog do Polo de Nova Friburgo já recebeu mais de 66 mil visualizações e tem nos mecanismos de busca (sites como Google e Yahoo!) sua maior fonte de visitas. Observou-se que o compartilhamento das postagens do blog em grupos no Facebook revelou ser uma estratégia importante, pois essa rede social agora é a segunda maior fonte de visitas do blog, tendo em alguns meses até ultrapassado os mecanismos de busca. 
Analisando os espaços mais visitados do blog (postagens ou páginas), percebe-se que posts informativos ou de divulgação de cursos e oportunidades e páginas interativas ou fontes de pes- quisa competem pelas primeiras posições de mais acessados.

Na Tabela 2 estão enumerados os cinco espaços mais visitados do blog, desconsiderando a página inicial.

Tabela 2: Posts e Páginas mais visualizados do blog do Polo de Nova Friburgo.

\begin{tabular}{l|c}
\hline \multicolumn{1}{c|}{ Post ou página } & Quantidade de visualizações \\
\hline Post sobre mudanças na Plataforma CEDERJ em $2012^{1}$ & mais de 4.200 \\
\hline $\begin{array}{l}\text { Página com enquête sobre a escolha do logo do projeto de extensão Ciência e Cultura também são feitas a } \\
\text { distância }\end{array}$ & mais de 3.600 \\
\hline Post divulgando cursos de extensão online oferecidos pela UFF ${ }^{3}$ & mais de 3.300 \\
\hline Post contendo informações sobre a Plataforma Freire & mais de 2.600 \\
\hline Página sobre palestra realizada no polo abordando o uso da Biotecnologia no combate à dengue ${ }^{5}$ & mais de 2.300 \\
\hline
\end{tabular}

Esses dados revelam as várias formas como o blog vem sendo explorado e demonstram a vasta potencialidade da utilização dessa ferramenta na educação: divulgação de oportunidades; aumento da interação de estudantes e comunidade com a instituição e seus projetos; produção e difusão de conhecimentos e complementação e expansão da abordagem feita em momentos presenciais de ensino, entre outros.

Nota-se, também, que as categorias Cursos (que agrupa postagens referentes à divulgação de cursos presenciais ou online do polo e de outras instituições) e CEDERJ (que agrupa postagens com notícias sobre o Consórcio, novos vestibulares etc.) são as mais visitadas do blog, seguidas por Notícias e Eventos. Isso demonstra os principais interesses dos leitores - que podem ser estudantes do polo ou não.

Analisando a interação dos leitores com o blog através das ferramentas disponíveis no WordPress, verificamos que 52 leitores seguem o blog por e-mail.

A Tabela 3 mostra a interação dos leitores via comentários.

\footnotetext{
1 As informações apresentadas nesse post foram de extrema relevância para os estudantes do Consórcio CEDERJ. A postagem pode ser vista em: http:// polofriburgo.wordpress.com/2012/01/24/nova-plataforma-cederj-2012/.

2 Com a escolha do logo do projeto de extensão, buscou-se maior interação entre alunos e comunidade. Disponível em: http://polofriburgo.wordpress. com/arquivo/2011-2\%C2\%BA-semestre/enquete-escolha-do-logo-do-projeto-de-extensao/.

3 Vale ressaltar que são referentes a cursos externos ao Polo de Nova Friburgo. Disponível em: http://polofriburgo.wordpress.com/2013/08/24/cursos-de-extensao-da-uff-na-modalidade-a-distancia/.

4 A Plataforma Freire divulga oportunidades de cursos de nível superior em todo o território nacional. Disponível em: http://polofriburgo.wordpress. com/2012/03/26/plataforma-freire-inscricoes-abertas-para-formacao-de-professores/.

5 Trata-se de um relato de evento realizado no polo. A abordagem do tema foi complementada pela equipe do blog com textos, imagens e vídeos e acabou se caracterizando como fonte de pesquisa sobre o assunto na internet. Disponível em: http://polofriburgo.wordpress.com/arquivo/2011-1\%C2\%BA-semestre/aplicacoes-da-biotecnologia-no-combate-a-dengue/.
} 
Tabela 3: Posts e Páginas com mais comentários e quantidade total de comentários no blog do Polo de Nova Friburgo

\begin{tabular}{l|c}
\hline \multicolumn{1}{c|}{ Local do Comentário } & Quantidade \\
\hline Comentários na página Enquête de escolha do logo do Projeto de Extensão & 56 \\
\hline Comentários no post Esperamos que você esteja bem $^{6}$ & 27 \\
\hline Comentários na página Dúvidas $^{7}$ & 21 \\
\hline Total de comentários em todo o blog & 248 \\
\hline
\end{tabular}

Com relação ao YouTube, os números ainda são discretos: 1.460 visualizações em pouco mais de dois anos de canal. Porém esse espaço só passou a apresentar conteúdos frequentes e mais elaborados em meados de 2013, sendo portanto um espaço relativamente novo.

As postagens do blog nos diversos grupos do $\mathrm{Fa}$ cebook foram curtidas, comentadas e compartilhadas por diversas pessoas, indicando a relevância de criar um espaço oficial do polo nessa rede, ou seja, uma página para compartilhar os resumos das postagens do blog, apresentando links que levem os leitores a visitálo e para facilitar o compartilhamento de imagens específicas e vídeos do YouTube. A criação desse espaço oficial deve gerar aumento da confiança dos leitores nos materiais do polo que são compartilhados nessa rede.

Na pesquisa de opinião foram coletadas 29 avaliações; 27 respondentes eram alunos, ex-alunos ou tutores do Polo de Nova Friburgo; um respondente era aluno de outro polo do CEDERJ e um respondente era aluno de pós-graduação da Universidade Federal Rural do Rio de Janeiro (UFRRJ). Por essas respostas foi possível verificar que:

- entre os que responderam sobre a relevância do blog, 22 consideraram o blog um trabalho relevante e apenas um considerou o trabalho irrelevante;
- 14 respondentes demonstraram compreender os objetivos do trabalho;

- 15 afirmaram que, em diversos momentos, o blog lhes foi útil, citando exemplos;

- 12 relataram ter conhecido o blog no próprio polo (em eventos, tutorias ou conversas com amigos); três, no Facebook; três, por pesquisas em motores de busca e um soube do blog pela Plataforma CEDERJ;

- 11 respondentes afirmaram saber que podiam receber atualizações do blog por e-mail, enquanto 11 afirmaram não saber;

- cinco afirmaram seguir o blog por e-mail; seis disseram acompanhar as novidades por conta própria (acessando a url diretamente); 10 afirmaram acessar as novidades pelo Facebook;

- 12 enumeraram pontos positivos do blog, como linguagem direta, organização simples e atualização constante;

- a frequência das atualizações foi relatada como ponto positivo em 12 avaliações, embora quatro respondentes tenham apontado a falta de atualizações frequentes como ponto negativo;

6 Este post foi lançado na época da tragédia de 2011, visando coletar informações sobre estudantes e funcionários do polo e oferecer um meio de comunicação entre a equipe. Disponível em: http://polofriburgo.wordpress.com/2011/01/15/esperamos-que-voce-esteja-bem/.

7 Página para os leitores comentarem suas dúvidas a respeito de algum tema que julguem ser pertinente ao Polo de Nova Friburgo. Disponível em: http://polofriburgo.wordpress.com/duvidas/. 
- quatro enumeraram outros pontos negativos, como a foto utilizada no cabeçalho e o leiaute (considerados pouco atrativos);

- cinco respondentes afirmaram que o blog não apresenta pontos negativos;

- 11 respondentes fizeram comentários e sugestões. Dentre os comentários, alguns parabenizaram a equipe pelo blog e pela avaliação proposta.

Vale ressaltar que o número de seguidores do blog aumentou após a realização da pesquisa de opinião.

\section{Considerações finais}

Desde sua implementação, a equipe de gestão do polo procurou proporcionar a seus estudantes atividades que articulem o ensino, a pesquisa e a extensão. Mesmo em momentos difíceis, como quando precisou funcionar em locais improvisados, o Polo de Nova Friburgo se caracterizou como espaço relevante para o desenvolvimento cultural de alunos e comunidade. Ao investir esforços em atividades de extensão, contribui-se para aumentar a visibilidade e a relevância da instituição na sociedade, além de garantir aos estudantes melhor formação.

Segundo Machado (2013), um problema recorrente em cursos de licenciatura a distância é que, quando oferecidos em cidades carentes cultural ou academicamente, os alunos têm dificuldade em cumprir a carga horária de atividades culturais complementares exigidas para sua diplomação. Essa carência não é notada no Polo de Nova Friburgo, justamente pelo esforço em oferecer atividades desse tipo, divulgar aquelas que são realizadas por outras instituições e estimular a participação dos estudantes, ações nas quais o blog possui papel fundamental.
Acredita-se que atividades de extensão universitária influenciem positivamente a adaptação dos estudantes ao meio acadêmico, o que pode contribuir ainda para a redução da evasão, problema muito discutido em estudos sobre a EaD (ALMEIDA, 2008; CORREAA; LACERDA, 2011; ESPÍNDOLA; LACERDA, 2013).

Este trabalho demonstra o potencial do blog na Educação, principalmente no que se refere à extensão universitária. Os comentários postados no blog do Polo de Nova Friburgo, na pesquisa de opinião e no Facebook revelam o interesse dos estudantes em se inserir mais no projeto do blog, seja aparecendo nas fotos postadas, contribuindo com sugestões, participando da elaboração de conteúdos ou disseminando os materiais pela internet.

O Facebook aparece como espaço com alto potencial para contribuir na realização dos objetivos do projeto do blog. A partir das experiências relatadas aqui, sugere-se a criação de um espaço oficial do Polo de Nova Friburgo nessa rede e que trabalhe em conjunto com o blog.

Os resultados do blog do Polo de Nova Friburgo demonstram que a utilização adequada de ferramentas da internet pode proporcionar uma extensão sem limites espaços-temporais, contribuindo para o desenvolvimento acadêmico, profissional, cultural e pessoal não apenas de seus estudantes, mas também da comunidade atingida. Dessa forma, pode-se dizer que a extensão universitária não só é possível na $\mathrm{EaD}$ como pode acontecer com qualidade.

Assim, conclui-se que a interação da instituição promotora de cursos com a comunidade pode e deve ocorrer na EaD e que seus resultados contribuem para o fortalecimento da ideia de que essa modalidade de ensino pode oferecer uma formação de qualidade para seus estudantes, tanto do ponto de vista curricular como pessoal, além de poder ser relevante cultural, artística e profissionalmente.

\section{Referências}

ALMEIDA, O. C. S. Evasão em cursos a distância: análise dos motivos de desistência. 2008. Disponível em: <http://www.abed.org.br/congresso2008/tc/552008112738PM.pdf>. Acesso em: 17 out. 2013. 
ALVES, L. Educação a Distância: conceitos e história no Brasil e no mundo. In: LITTO, F. M. (Org). Revista Brasileira de Educação Aberta e a Distância (RBEAD), v. 10, 2011, p. 83-92. Disponível em: <http:// www.abed.org.br/revistacientifica/Revista_PDF_Doc/2011/Artigo_07.pdf > . Acesso em: 14 out. 2013.

ARAUJO, S. C. et al. Ciência e Cultura também são feitas a distância. V Congresso Brasileiro de Extensão Universitária (V CBEU), Porto Alegre, 2011. 5 p.

BOHADANA, E.; VALLE, L. O quem da educação a distância. Revista Brasileira de Educação [online]. 2009, v. 14, n. 42, p. 551-564. Disponível em: <http:/www.scielo.br/pdf/rbedu/v14n42/v14n42a11.pdf>. Acesso em: 29 mai. 2014.

BRASIL, Constituição Federal de 1988. Disponível em: <http://portal.mec.gov.br/setec/arquivos/pdf legislacao/superior/legisla_superior_const.pdf>. Acesso em: 15 out. 2013.

CORREAA, P. S.; LACERDA, F. K. D. EaD e evasão no Polo EaD de Nova Friburgo: identificando causas e propondo soluções. VIII Congresso Brasileiro de Ensino Superior a Distância (VIII ESUD), Ouro Preto, 2011. 11 p.

ESPÍNDOLA, R. M.; LACERDA, F. K. D. Evasão na educação a distância: um estudo de caso. Revista EaD em foco. Fundação Cecierj, v. 3, n. 1, p. 96-108, 2013. Disponível em: < http://eademfoco.cecierj.edu.br/index. php/Revista/article/view/174/45>. Acesso em: 01 abr. 2014.

FORPROEX, Fórum de Pró-Reitores de Extensão. Política Nacional de Extensão Universitária. Manaus, 2012.

GOMES, M. J. Blogs: um recurso e uma estratégia pedagógica. VII Simpósio Internacional de Informática Educativa, SIIE, p. 311-315. 2005. Disponível em: < http://repositorium.sdum.uminho.pt/ bitstream/1822/4499/1/Blogs-final.pdf>. Acesso em: 15 out. 2013.

GRANATO, T. M. et al. O destino dos alunos egressos de cursos oferecidos através do Consórcio CEDERJ. Relatório de pesquisa de egressos formados 2005-2009. Rio de Janeiro: Fundação CECIERJ/ Consórcio CEDERJ, 2010.

LACERDA, F. K. D. Relatando experiências em EaD: o caso do Polo de Nova Friburgo. In: BRUNO, M.; RITTO, A. (org.). Educação a Distância: flexibilidade e paradigmas. Rio de Janeiro: PoD, 2010, p. 145-170.

LÉVY, P. Cibercultura. Rio de Janeiro: Editora 34, 1997.

LOPES, M. C. L. P. et al. O processo histórico da Educação a Distância e suas implicações: desafios e possibilidades. 2007. Disponível em: <http://www.histedbr.fae.unicamp.br/acer_histedbr/jornada/jornada7/. Acesso em: 25 abr. 2013.

LÜCK, Esther Hermes. Educação a distância: contrapondo críticas, tecendo argumentos. Educação, Porto Alegre, v. 31, n. 3, p. 258-267, set./dez. 2008. Disponível em: <http://revistaseletronicas.pucrs.br/ojs/index.php/ faced/article/download/4480/3399>. Acesso em: 2 mai. 2014.

MACHADO, M. R. L. et al. A importância dos programas de extensão para formação universitária a distância. $\mathbf{X}$ Congresso Brasileiro de Ensino Superior a Distância (X ESUD). Belém, 2013. Disponível em: <http:// www.aedi.ufpa.br/esud/trabalhos/oral/AT2/114337.pdf>. Acesso em: 14 out. 2013.

PINHO JÚNIOR, S. R.et al. Utilização do blog na ampliação de fronteiras na universidade. V Congresso Brasileiro de Extensão Universitária (V CBEU), Porto Alegre, 2011.

PINHO JÚNIOR, S. R.; OLIVEIRA, A. N. A utilização do blog como ferramenta educacional. I Seminário das disciplinas pedagógicas das Licenciaturas EaD-UERJ, Rio de Janeiro, 2013.

PINHO JÚNIOR, S. R. et al. A EaD expandindo as fronteiras da universidade: o blog em questão. Anais do I Etarsserra, UFF, Nova Friburgo, p. 14-15, 2013. Disponível em: <http://etarserrauff.wix.com/punf > . Acesso em: 14 out. 2013. 
SILVA, F. M. Blogosfera: um estudo dos blogueiros a partir dos blogs mais acessados do país. Estudos semióticos, v. 6, n. 1, p. 54-64, jun. 2010.

UFPA. Pró-Reitoria de Extensão. Política de Extensão do Fórum de Pró-Reitores de Extensão. Disponível em: <http://proex.ufpa.br/PRINCIPAL/index.php/politica-de-extensao>. Acesso em: 15 out. 2013. 